$<$

$-$

$\sim$

\title{
Effect of a retailer intervention on cigarette sales to minors in San Diego County, California
}

\author{
Karen D Keay, Susan I Woodruff, Marianne B Wildey, Erin M Kenney
}

\begin{abstract}
Objective - To assess the effectiveness of a retailer educational campaign in reducing the illegal sale of cigarettes to minors in San Diego County, California, USA.

Design-A pre-test-post-test control group design to study the effects of the programme, including information on sales rates to minors and sales activity. Setting - A variety of store types in ethnically diverse communities in San Diego County.

Subjects -260 retail outlets.

Primary interventions - Direct retailer education, mass media, and grass roots work within the community.

Main outcome measures-Cigarette sales to minors.

Results -260 stores were visited by minors, aged 12-17 years, with the intent of purchasing cigarettes. The minors were successful at $69.9 \%$ of the stores surveyed. The percentage of stores illegally selling cigarettes to minors was significantly reduced (to $32.2 \%$ ) in the 143 stores which had received retailer education one month after the intervention ended. Control stores also showed a slight, nonsignificant, reduction $(59.0 \%)$. Conclusion-An intensive retailer educational programme can have a significant effect in reducing the illegal sales rate of cigarettes to minors.

(Tobacco Control 1993; 2: 145-151)
\end{abstract}

Introduction

It is well known that nicotine addiction is usually established during childhood and adolescence. ${ }^{1}$ In addition, more than six million Americans under the age of 18 use tobacco. Minors consume an estimated 947 million packs of cigarettes yearly, producing over $\$ 1$ billion annually in illegal tobacco revenues. ${ }^{2}$ Many agree that if the decision to smoke can be delayed until adulthood, choosing to become a smoker is less likely, as only a small percentage $(10 \%)$ of smokers begin to smoke after the age of $25 .^{3}$

Because the ease with which cigarettes can be purchased influences the decision to smoke, laws governing minors' access to tobacco can be an effective tobacco control strategy. ${ }^{4}$ Laws regulating the sale of tobacco products to minors, now in effect in 46 states, differ from state to state. ${ }^{5}$ In California, it is against the law to sell tobacco products to anyone under the age of 18. Retailers violating this law are subject to a misdemeanor with a first offence fine of $\$ 200$, a second offence fine of $\$ 500$, and a third offence fine of $\$ 1000$. Minors caught purchasing tobacco are subject to a $\$ 50$ fine and/or 25 hours of community service work (Penal Code 308). Although it is illegal in most states to sell tobacco to minors, tests conducted around the nation show that minors can buy cigarettes in approximately $70 \%$ of all retail outlets. ${ }^{6-12}$

Educating retailers on tobacco distribution laws is crucial in obtaining their cooperation and compliance with laws that restrict minors' access to tobacco. ${ }^{11}$ Retailer intervention studies have shown that education aids in changing retailers' behaviour. Although direct retailer education has not been extensively applied to tobacco sales, the strategy has been effective in changing retailer behaviour related to alcohol sales. One study showed that employees who participated in a sales assistant intervention training programme initiated more customer interventions, such as checking identification, than did untrained sales assistants. ${ }^{13}$ Another study reported that after attending a training programme for sales assistants and managers, outright refusal of service for alcohol increased from $3 \%$ pre-test to $16 \%$ post-test. ${ }^{14}$ Although sales assistant training programmes for alcohol sales are somewhat different to retailer education for tobacco sales, the desired behaviour of checking identification is the same.

There is some evidence that educational interventions aimed at retailers can reduce tobacco sales to underage youths. Following a six-month campaign in Santa Clara County, California, which employed community education, direct retailer education, and contact with corporate executives, overall sales of cigarettes to minors was reduced from $74 \%$ to $39 \%{ }^{6}$ Although the study did not include a no-treatment control group, comparisons among three types of intervention combinations indicated no differential effect on sales as a function of the intensity (eg, community education only versus community education with direct merchant education) of the intervention.

The purpose of the present study was to assess the effectiveness of Project TRUST (Teens and Retailers United to Stop Tobacco), a multi-level retailer intervention aimed at 
reducing the illegal sale of cigarettes to minors. Primary intervention components included direct retailer education as well as mass media and community components directed at increasing community awareness of the problem. A pre-test - post-test control group design was employed to assess the effects of the programme on a variety of store types and ethnically diverse communities.

\section{Methods \\ SETTING}

Project TRUST, based at San Diego State University (SDSU), sub-contracted with five community-based organisations to participate in an effort to decrease tobacco sales to minors. The organisations included two community health clinics and three community development agencies. Through these organisations, the TRUST intervention was implemented in six low-income, ethnically diverse areas in San Diego County, including one predominantly Asian (site 3), one AfricanAmerican (site 5), one Anglo (site 2), and three Hispanic (sites 1, 4, and 6) communities. The median income in San Diego County is $\$ 35022$ and $75 \%$ of the population is Caucasian. ${ }^{15}$ The areas receiving the TRUST intervention were lower in socio-economic status and the percentage of population of Caucasian descent. In site 3 , the median income is $\$ 27039 ; 42 \%$ of the population are Caucasian, and $34 \%$ are Asian. In site 5, the median income is $\$ 15380$; $14 \%$ of the residents are Caucasian, and $54 \%$ are of African-American descent. In site 2, the median income is $\$ 20370$ and $84 \%$ of the population are Caucasian. In sites 1,4 , and 6 the median income is $\$ 23349$ and $50 \%$ are Hispanic. ${ }^{15}$ Four of the community organisations were responsible for one site each, and one organisation was responsible for two sites. These diverse sites were selected as it has been shown that tobacco companies have increasingly targeted low-income and ethnic populations, with greater advertising in Asian and African-American communities than in Anglo or Hispanic areas. ${ }^{16}$

Staffing for Project TRUST consisted of six full-time Site Coordinators and six part-time graduate student assistants hired by the community organisations to work in their respective communities. Site Coordinators were selected based on their previous experience working within the targeted communities. In the African-American site, the staff was bicultural, as was the case in the Hispanic sites. Directed by a Project Director at the contracting agency, Site Coordinators and assistants were responsible for managing TRUST implementation and evaluation-related efforts, including (a) recruiting, training, and supervising pairs of teen-adult volunteers to attempt to purchase cigarettes at stores both pre- and post-intervention; (b) providing face-to-face retailer education; and (c) conducting community presentations and local media events for the purpose of increasing awareness about youth access to tobacco. Additionally, there was a Principal Investigator and two half-time Project Managers, from SDSU, who were responsible for coordinating all project-related activities among sites.

\section{RESEARCH DESIGN}

Using information from the San Diego County Department of Health Services, Environmental Health Services Division, and a 1980 census map, 314 stores among the six sites were identified for participation in the present study. The four store-types included in this study were petrol service stations/convenience stores $(n=94)$, off-licences or liquor stores $(n=78)$, independent groceries $(n=115)$, and supermarkets $(n=27)$. These store types were selected rather than others (eg, discount stores and pharmacies) because these types are thought to be more often visited by youth. While four of the targeted sites had an even distribution of all store types, the AfricanAmerican and one Hispanic site had a larger number of independent groceries and a smaller number of supermarkets.

To assign stores to intervention and control conditions, maps of the areas around the six site headquarters were obtained. Concentric circles of two-mile and five-mile radius from the headquarters were drawn. All stores that fell within the inner radius were assigned as intervention stores and those that fell within the outer radius were assigned as controls. Clustering of stores by location was used rather than random assignment to guard against exposure of the control stores to the intervention and to maximise the effects of the intervention as retailers would be more receptive to the intervention if neighbouring stores were also participating.

All the stores identified for the study were sent a passive consent form by registered mail instructing the owner or manager to return the form only if she or he refused to participate. The consent form was required by the SDSU human subjects committee because the study involved collecting retailer questionnaire data. Of the 314 stores identified, 34 declined to participate prior to the beginning of the study. Analysis showed no difference by store type in the percentage of stores that declined. However, significant differences were found by site, with the percentage of stores declining to participate ranging from $0 \%$ in the AfricanAmerican community to $21 \%$ in the Asian Community. Stores receiving retailer education (intervention stores; $n=144$ ) received the TRUST programme, described in greater detail below. Control stores $(n=136)$ received no TRUST intervention.

We hypothesised that, following the retailer educational programme and community/ media campaign, intervention stores would sell tobacco to minors less frequently than control stores. Further, we anticipated that control stores would show a slight reduction in tobacco sales to minors due to media exposure and word-of-mouth, but that this change would not be of the magnitude observed among intervention stores. 
EVALUATION PROCEDURES, DATA COLLECTION, AND MEASURES

Project staff from the six sites recruited 70 twoperson teams of teenage (12- to 17-year-olds) and adult volunteers to survey participating stores prior to and following the TRUST intervention. Attempts were made to recruit parent-child teams from local community organisations, schools, and youth groups with ethnic characteristics representative of the area. The teams attended a two-hour training conducted by Project staff where both adults and minors learned about the health consequences of tobacco use and the data collection protocol. After signing informed consent forms, the volunteers were randomly assigned to stores where minors, accompanied by adults, attempted to purchase cigarettes. The teams were blind as to the experimental condition of the stores they visited. The average number of stores visited by the teams was six (range of 2-14) stores. Results were recorded on Sales Outcome Reports (SOR), with the outcome of the purchase attempt recorded as either a one (successful purchase) or a zero (no purchase). Minors also recorded information about sales activities, including some measures used by Altman and colleagues ${ }^{6}:$ (a) whether the sales assistant asked for the minor's identification, (b) whether the sales assistant asked the minors age, (c) whether the sales assistant said nothing to the minor, (d) whether the sales assistant asked if the cigarettes were for the minor's own use, (e) whether the sales assistant encouraged the minor's tobacco use (eg, offered matches), and (f) whether the sales assistant discouraged the minor's use of tobacco (eg, stated the adverse health effects). All sales activity measures were dichotomous variables with 0 indicating the activity did not occur, and 1 indicating that the activity occurred. The adult's role during the purchase attempts was primarily to drive the minor to the stores, to help complete the SOR, and to intervene if any problems arose.

Protocols for purchasing cigarettes differed slightly among the six sites. In four of the targeted areas, underage minors were permitted by the police department to actually purchase cigarettes. In this case, the outcome measure was whether or not the minor left the store with the cigarettes. In the other two sites, minors were only allowed to attempt to purchase cigarettes. The minor would ask for a package of cigarettes, and when the sale was rung on the cash register, the minor would inform the sales assistant that he/she did not have enough money to purchase the cigarettes. When this protocol was used, a sale was considered successful if the shop assistant rang up the transaction. Minors were instructed not to lie if sales assistants asked their age. During the purchase attempts, neither the retailers nor the sales assistant were aware of the undercover buying operation. Pre-intervention purchase attempts took place in November 1990, and post-intervention attempts took place one year later in November 1991, one month following the conclusion of the intervention.

\section{TRUST INTERVENTION}

The TRUST intervention was designed to improve merchant compliance with tobacco laws restricting sales to minors by direct retailer education, media, and community involvement. The one-year retailer educational campaign was conducted by Project staff and San Diego County Environmental Health Officer Inspectors. Following TRUST's baseline survey of cigarette sales to minors, Environmental Health Field Inspectors conducted a 10-minute on-site discussion with all non-compliant retail managers and/or owners, addressing the issues of tobacco sales to minors and the results of the SOR. Environmental Health field staff were used because they are seen as figures of authority able to levy fines on retailers. In addition, we wanted to test the feasibility of involving them in retailer education efforts.

Using educational materials that had been reviewed by retail corporations and a community advisory coalition, TRUST staff personally visited all 143 intervention retailers three times, on a quarterly schedule. These face-to-face educational presentations lasted approximately 15 minutes and were conducted with either store owners or managers. Site Coordinators presented the content of the educational packet and emphasised the ethical and legal obligation of merchants to restrict tobacco sales to minors. Two weeks after each of the three presentations, staff returned to the stores to answer questions, distribute extra materials if needed, and to discuss compliance with the law.

Table 1 provides a list of the materials that were developed, grouped by target population. The first visit was designed to increase owners'/managers' awareness and knowledge about tobacco laws pertaining to minors, facts about youth and tobacco, and the importance of training sales assistants on this issue. One particularly useful item described the fines and infractions involved when the law is violated.

The goal of the second session was to educate sales assistants about the youth access issue.

\section{Table 1 Educational materials}

\begin{tabular}{|c|c|}
\hline Target population & Item \\
\hline Manager/Owner & $\begin{array}{l}\text { Cover letter } \\
\text { Project summary } \\
\text { Copy of state law } \\
\text { Fines \& infractions breakdown } \\
\text { List of Advisory Coalition members } \\
\text { Fact sheet } \\
\text { Tips on training employees } \\
\text { Local smoking ordinance } \\
\text { Tobacco advertising information } \\
\text { Surgeon General's warning stickers } \\
\text { Newspaper articles } \\
\text { Copy of paid ads }\end{array}$ \\
\hline Sales assistant & $\begin{array}{l}\text { "How to check ID" brochure } \\
\text { Pay check stuffer summarising laws } \\
\text { Training video } \\
\text { Video quiz } \\
\text { Employee agreement }\end{array}$ \\
\hline Customers & $\begin{array}{l}\text { TRUST window placard } \\
\text { State law stickers } \\
\text { Age sticker } \\
\text { Parent note pad } \\
\text { Open/Closed sign } \\
\text { No smoking sign }\end{array}$ \\
\hline
\end{tabular}


This presentation included a 9-minute sales assistant training video produced by TRUST and a brochure instructing sales assistants on how to check identification and recognise fake identification, and how to say "no" to persistent teenagers. To ensure that all owners/managers watched the video, some staff brought a portable television and video recorder to the store and showed the video to the manager during the educational session. Owners/managers were asked to show the video and train their sales assistants. If stores did not have access to a video recorder for employee training, TRUST suggested a system that would enable employees to take the video home for viewing.

The final session focused on tobacco advertising and the role of the retailer in the community. A promotional item, an Open/ Closed sign which stated that proof of identity is required for tobacco and alcohol sales and that the shop supports tobacco-free teens, was provided to retailers as were window/counter stickers that stated the year the customer must be born to purchase either tobacco or alcohol. Most materials were available in English and Spanish.

Some materials required display on the premises such as the TRUST window placards, state law stickers, age stickers, Open/Closed signs, and no-smoking signs most of which were concentrated on or near the cash register and in the store's front window. All materials were provided free to retailers.

In addition to direct retailer education, TRUST employed community education and media strategies to encourage retailer compliance and to promote community awareness. The project held 13 community events, addressed 130 community organisations, and generated news stories about TRUST activities. TRUST staff held two press conferences to announce the pre-test and post-test results. At these events, various community members spoke, including government officials, parent-teacher association representatives, and members of community-based health organisations. In addition, TRUST sponsored various community events, including a Tobacco-Free Youth Conference and a community-wide "Why I want to be Tobacco Free" poster contest. Additionally, Site Coordinators attempted to mobilise families within the community to write letters of support to compliant retailers, to congratulate retailers that displayed TRUST materials, and to participate in other TRUST activities. A variety of media channels were used to increase public awareness of the youth access problem. TRUST generated seven newsletters sent to intervention retailers, adult and teenage volunteers, and local community decision-makers; 33 newspaper articles; 25 public service announcements; and 14 radio and television interviews. News articles printed about TRUST's efforts were given to retailers during the presentations to reinforce community involvement. To reward compliant retailers, TRUST placed a paid advertisement in the city newspaper thanking retailers (by name and address) who did not sell during the preand post-intervention purchase attempts.

\section{STATISTICAL ANALYSIS}

Of the 292 stores initially identified, postintervention data were collected for $89 \%$ ( $n=$ 260 ; intervention stores, $n=143$; control stores, $\mathrm{n}=117$ ). The 32 stores lost to followup had closed prior to the post-assessment. McNemar tests for dependent samples were conducted using the 260 matched cases to determine whether the percentage of intervention and control stores selling cigarettes to minors changed pre-test to post-test. Tests were also performed by site and store type (ie, petrol service stations/convenience, liquor, supermarket, and independent grocery) to assess differential intervention effects. Changes in sales activities (ie, whether or not the sales assistant asked for proof of identity, asked age, asked whether the cigarettes were for the minor's own use, encouraged or discouraged cigarette use) were investigated. Finally, chisquare analyses were conducted to assess other factors (gender and age characteristics) associated with sales.

\section{Results}

There were no significant differences in sales outcome for attempted purchases versus actual purchases; therefore, all data were combined to give an overall sales rate. Overall cigarette sales to minors over time is shown in the figure. A significant difference between sales rate at intervention and control stores was not seen at baseline, but cigarette sales to minors decreased at intervention stores from $69.9 \%$ at baseline to $32.2 \%$ post-test, a significant change $\left(\chi^{2}=35.11, p<0.001\right)$. While the sales rate at control stores dropped only slightly (from $65.0 \%$ pre-test to $59.0 \%$ post-test); this decline was not statistically significant.

Table 2 presents pre- and post-intervention sales rates by condition and store type. Pre-test sales rates for intervention stores ranged from $50.0 \%$ to $72.1 \%$. Sales rates for control stores ranged from $58.3 \%$ to $73.0 \%$. Changes in cigarette sales for each of the store types were more pronounced in intervention stores than among controls. Independent groceries, petrol service stations and convenience stores, and liquor stores participating in the intervention all showed significant reductions in cigarette sales. Intervention supermarkets also showed a

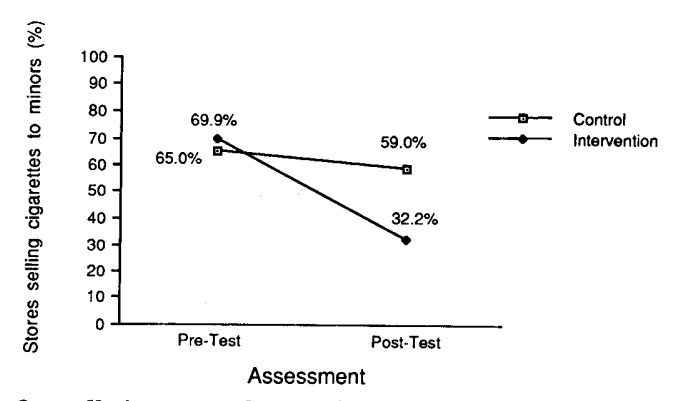

Overall cigarette sales to minors 
Table 2 Pre-and post-test sales rates by store type. I = Intervention stores; $C=$ control stores $; n s=$ not significant

\begin{tabular}{|c|c|c|c|c|c|c|c|c|c|c|c|}
\hline \multirow{2}{*}{$-i$} & \multirow{2}{*}{ Store type } & \multicolumn{2}{|c|}{ No. of stores } & \multicolumn{2}{|c|}{ Pre-test ${ }^{\star}$} & \multicolumn{2}{|c|}{ Post-test ${ }^{\star}$} & \multicolumn{2}{|c|}{$p$} & \multicolumn{2}{|c|}{$\%$ change $e^{\star \star}$} \\
\hline & & $I$ & $C$ & $I$ & $C$ & $I$ & $C$ & $I$ & $C$ & $I$ & $C$ \\
\hline & $\begin{array}{l}\text { Supermarket } \\
\text { Grocery } \\
\text { Petrol Station/ } \\
\text { Convenience }\end{array}$ & $\begin{array}{r}8 \\
59 \\
43\end{array}$ & $\begin{array}{l}12 \\
37 \\
31\end{array}$ & $\begin{array}{l}50.0 \\
71.2 \\
72.1\end{array}$ & $\begin{array}{l}58.3 \\
73.0 \\
61.3\end{array}$ & $\begin{array}{l}12.5 \\
35.6 \\
30.2\end{array}$ & $\begin{array}{l}41.7 \\
59.5 \\
61.3\end{array}$ & $\begin{array}{c}\text { ns } \\
0.001 \\
0.001\end{array}$ & $\begin{array}{l}\text { ns } \\
\text { ns } \\
\text { ns }\end{array}$ & $\begin{array}{l}-75.0 \\
-50.0 \\
-58.0\end{array}$ & $\begin{array}{c}-28.5 \\
-18.5 \\
0\end{array}$ \\
\hline & Off-licence & 33 & 35 & 69.7 & 65.7 & 33.3 & 65.7 & 0.01 & ns & -52.2 & 0 \\
\hline
\end{tabular}

$\star$ Percentage of stores that sold cigarettes to minors

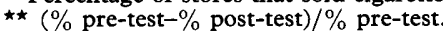

Table 3 Pre- and post-test sales rates by site. $I=$ Intervention stores; $C=$ control stores; $n s=$ not significant

\begin{tabular}{|c|c|c|c|c|c|c|c|c|c|c|}
\hline \multirow[b]{2}{*}{ Location } & \multicolumn{2}{|c|}{ No. of stores } & \multicolumn{2}{|c|}{ Pre-test ${ }^{\star}$} & \multicolumn{2}{|c|}{ Post-test ${ }^{\star}$} & \multicolumn{2}{|c|}{$p$} & \multicolumn{2}{|c|}{$\%$ change $e^{\star \star}$} \\
\hline & $I$ & $C$ & $I$ & $C$ & $I$ & $C$ & $I$ & $C$ & $I$ & $C$ \\
\hline $\begin{array}{l}\text { Site } 1 \\
\text { Site } 2 \\
\text { Site } 3 \\
\text { Site } 4 \\
\text { Site } 5 \\
\text { Site } 6\end{array}$ & $\begin{array}{l}19 \\
26 \\
27 \\
24 \\
21 \\
26\end{array}$ & $\begin{array}{l}11 \\
21 \\
20 \\
27 \\
22 \\
16\end{array}$ & $\begin{array}{l}89.5 \\
76.9 \\
59.3 \\
75.0 \\
38.1 \\
80.8\end{array}$ & $\begin{array}{l}90.9 \\
61.9 \\
60.0 \\
66.7 \\
45.5 \\
81.3\end{array}$ & $\begin{array}{l}21.1 \\
26.9 \\
40.7 \\
20.8 \\
57.1 \\
26.9\end{array}$ & $\begin{array}{l}45.5 \\
66.7 \\
70.0 \\
51.9 \\
50.0 \\
68.8\end{array}$ & $\begin{array}{c}0.001 \\
0.001 \\
\text { ns } \\
0.001 \\
\text { ns } \\
0.001\end{array}$ & $\begin{array}{l}\text { ns } \\
\text { ns } \\
\text { ns } \\
\text { ns } \\
\text { ns } \\
\text { ns }\end{array}$ & $\begin{array}{l}-76.4 \\
-65.0 \\
-31.3 \\
-72.3 \\
+49.9 \\
-66.7\end{array}$ & $\begin{array}{r}-49.9 \\
+7.8 \\
+16.7 \\
-22.2 \\
+9.9 \\
-15.4\end{array}$ \\
\hline
\end{tabular}

$\star$ Percentage of stores that sold cigarettes to minors.

$\star \star$ ( $\%$ pre-test- $\%$ post-test $) / \%$ pre-test.

Table 4 Sales activities in intervention $(I)$ and control $(C)$ stores. ID $=$ proof of identity; $n s=$ not significant

\begin{tabular}{|c|c|c|c|c|c|c|c|c|c|c|}
\hline \multirow[b]{2}{*}{ Activity } & \multicolumn{2}{|c|}{ No of cases } & \multicolumn{2}{|c|}{ Pre-test $t^{\star}$} & \multicolumn{2}{|c|}{ Post-test* } & \multicolumn{2}{|c|}{$p$} & \multicolumn{2}{|c|}{$\%$ change ${ }^{\star \star}$} \\
\hline & $I$ & $C$ & $I$ & $C$ & $I$ & $C$ & $I$ & $C$ & $I$ & $C$ \\
\hline Asked nothing & 143 & 115 & 71.3 & 62.6 & 33.6 & 53.0 & 0.001 & ns & -52.9 & -15.3 \\
\hline Asked for ID & 143 & 115 & 13.3 & 9.6 & 48.3 & 19.1 & 0.001 & 0.05 & +263.2 & +98.9 \\
\hline Asked age & 143 & 115 & 14.7 & 15.7 & 27.3 & 27.0 & 0.01 & ns & +85.7 & +72.0 \\
\hline $\begin{array}{l}\text { Asked if cigarettes } \\
\text { for own use }\end{array}$ & 143 & 115 & 2.1 & 2.6 & 2.8 & 7.0 & ns & ns & +33.3 & +169.2 \\
\hline $\begin{array}{l}\text { Discouraged use of } \\
\text { cigarettes }\end{array}$ & 143 & 115 & 4.2 & 9.6 & 17.5 & 7.0 & 0.001 & ns & +316.7 & +27.1 \\
\hline $\begin{array}{l}\text { Encouraged use of } \\
\text { cigarettes }\end{array}$ & 140 & 115 & 15.7 & 13.0 & 8.6 & 12.2 & ns & ns & -45.2 & -6.2 \\
\hline
\end{tabular}

* Percentage of stores engaging in activity.

$\star \star$ ( $\%$ pre-test- $\%$ post-test $) / \%$ pre-test. ification. Furthermore, changes on the other two measures, asking if cigarettes were for the minor's own use and encouraging minor's use of cigarettes, although not significant, were in a direction that supported an intervention effect.

At baseline, the sex of the surveyor was significantly related to sales of cigarettes to minors $\left(\chi^{2}=4.28, p \leqslant 0.05\right)$; ie, females found it easier to purchase cigarettes than males $(72.3 \%$ versus $59.6 \%)$. At post-test, these differences disappeared, with females and males equally able to purchase cigarettes $(42.4 \%$ versus $44.8 \%)$. The age of the surveyor (treated as discrete one-year categories from 12 to 17 years of age) was significantly related to cigarette sales at baseline $\left(\chi^{2}=\right.$ $41.20, \mathrm{p}<0.001)$ and at post-test $\left(\chi^{2}=12.85\right.$, $\mathrm{p}<0.05$ ). At each time, younger minors had a harder time purchasing cigarettes than older ones.

\section{Discussion}

The TRUST educational campaign proved effective in reducing over-the-counter cigarette sales to minors. In the majority of the targeted areas, stores exposed to the educational intervention showed a significant decline in illegal cigarette sales rates not evident among control stores. The present study demonstrated that an intensive educational campaign, in conjunction with a broad-based media campaign and community involvement, can reduce illegal cigarette sales in a variety of store types and in diverse communities. The overall results indicated a sales rate decrease of $53.9 \%$ for intervention stores.

A concern with the present study is that minors were instructed not to lie if the sales assistants asked their age. Both the police department and SDSU's review committee for the protection of human subjects required this procedure. It is likely that the majority of minors, if confronted about their age, would lie to the retailer and say that they were 18 years old or older. Therefore, our results may underestimate the true rate at which retailers sell cigarettes to minors in San Diego.

The intervention proved effective in all of the geographic locations except the predominantly African-American neighbourhood (Site 5). The explanation for the lack of success in this community is difficult to identify in light of the fact that data collection procedures and intervention protocols in all six areas were similar. There are several hypotheses for the ineffectiveness: (a) language barriers between the sales assistants and TRUST staff; relative to other areas, this area had a higher percentage of retailers from non-English- or Spanishspeaking countries; (b) a greater acceptability of tobacco use in the countries of origin of the sales assistants; and (c) a chance finding due to the small number of cases in this site. However, these hypotheses do not explain the higher sales rate among intervention stores in this area relative to control stores. Further research is being done to investigate this finding.

The Asian community (site 3 ) showed a proof of identity doubled from prenotably on those related to discouraging minors' use of cigarettes and asking for ident- 
reduction in cigarette sales to minors. However, the reduction was less than that seen in Anglo (site 2) and Hispanic communities (sites 1,4 and 6) and was not statistically significant. A plausible explanation for the relatively low improvement could be that English-language materials were delivered to this community, while materials translated into Vietnamese may have been more appropriate.

The TRUST intervention proved highly effective in the Hispanic areas for a number of possible reasons: (a) most of the materials were available in Spanish, (b) the staff presenting the materials were bi-cultural and bilingual, (c) the sales assistants and managers working in Hispanic areas were also of Hispanic descent, and (d) police may have been more actively involved in Hispanic communities.

The control stores showed a $9.2 \%$ reduction in the sales rate overall, supporting our initial hypothesis that sales in control stores would decrease slightly as a result of information from the media and word-of-mouth. This hypothesis was best supported in the Hispanic communities compared to the AfricanAmerican, Asian, and Anglo communities. This may be partly due to the fact that the San Diego Hispanic communities are thought to be close knit and youth-oriented. Intervention and control store merchants in the Hispanic areas may have shared information about TRUST's retailer and community efforts with each other. However, this non-significant decrease in tobacco sales by control stores suggests that a media campaign alone appears to have little impact on merchant behaviour. An assessment of the effects of long-term exposure to media should be conducted.

One disappointing aspect of the TRUST intervention was the inability to mobilise families within the community. Despite intensive efforts, we were unable to convince parents to write letters to complain to retailers or to congratulate stores that displayed project materials. Because there are constraints on parents' time, making pre-printed letters and materials available to them might have encouraged parental involvement in communitybased efforts.

Based on anecdotal evidence from retailers, placing a paid advertisement in the newspaper was well received and seemed to facilitate reducing cigarette sales to minors. A negative approach, listing the names and addresses of stores that sold cigarettes during spot checks, may also be effective.

Our method of three intensive educational visits proved effective, but may not be feasible on a larger scale. Most large communities would find it difficult to implement a programme such as Project TRUST without adequate funding. One way to implement the TRUST educational intervention in a large community would involve using Environmental Health Officers. This approach is an excellent avenue for providing and institutionalising retailer education because field staff already visit many retailers and have developed a working relationship with them, and they are viewed as authoritative because they can levy fines for violations. Such a self-sufficient retailer educational programme could be established through fee-for-service, or supporied from vendor licensing fees.

While the present results are encouraging, even after the intervention there remained a $30 \%$ over-the-counter sales rate to minors. In addition, one study has reported a rebound of sales following an intervention without benefit of boosters and enforcement. ${ }^{17}$ Police enforcement is one way to combat illegal cigarette sales to minors and, moreover, can help sustain progress that has been achieved through merchant education programmes. ${ }^{7,10,18}$ Researchers have argued that active enforcement is the only cost-effective intervention to reduce youth access. ${ }^{71}$ However, in San Diego County we found that there were practical limitations to the use of police enforcement, such as lack of police funds, personnel, and willingness of police departments to conduct tobacco sting operations. To overcome these barriers, we conducted retailer education and used the results from our purchase attempts to help make this issue a priority with the police.

In summary, a retailer intervention consisting of an intensive retailer education component accompanied by a community/media campaign can result in dramatic reductions in tobacco sales to minors. However, it is doubtful that any single strategy can effectively stop minors' access to tobacco altogether. Future efforts to reduce youth access to tobacco should implement and explore the effectiveness of increasing enforcement of current tobacco laws and/or institutionalising on-going educational campaigns.

The funding for this work was provided by the Tobacco Tax Health Protection Act of 1988-Proposition 99, under grant number 90-10960 from the State of California. The authors gratefully acknowledge the contributions of Dr Felipe Castro, Nadia Campbell, Site Coordinators, Graduate Assistants, other support staff and volunteers.

1 Centers for Disease Control. Differences in the age of smoking initiation between blacks and whites - United States. MMWR 1991; 40: 754-7.

2 DiFranza JR, Tye JB. Who profits from tobacco sales to children? f $A M A$ 1990; 263: 2784-7.

3 Burns D, Pierce JP. Tobacco Use in California 1990-1991. Sacramento: California Department of Health Services, 1992: 99-115.

4 US Department of Health and Human Services. Smoking and Health in the Americas: a 1992 report of the Surgeon General, in collaboration with the Pan American Health Grenal, in collaboration with the Pan American Health

5 Choi WS, Novotny TE, Thimis AT. Restricting minors access to tobacco: a review of state legislation, 1991. Am access to tobacco: a review of
f Prev Med 1992; 8: 19-22

6 Altman DG, Foster V, Rasenick-Douss L, Tye JB. Reducing the illegal sale of cigarettes to minors. $\mathscr{f} A M A$ $1989 ; 261: 80-3$.

7 Jason LA, Ji PY, Anes MD, Birkhead SH. Active enforcement of cigarette control laws in the prevention of cigarette sales to minors. FAMA 1991; 266:3159-61.

8 Forster JL, Hourigan M, McGovern P. Availability of cigarettes to underage youth in three communities. Prev Med 1992; 21:320-8.

9 Erickson AD, Woodruff SI, Wildey MB, Kenney EM. A baseline assessment of cigarette sales to minors in San Diego, California. $f$ Commun Health (in press).

10 Feighery $\mathrm{E}$, Altman DG, Shaffer $\mathrm{G}$. The effects of combining education and enforcement to reduce tobacco combining education and enforcement to red
sales to minors. $¥ A M A 1991 ; 266: 3168-71$

11 DiFranza Jr, Norwood BD, Garner DW, Tye JB. Legislative efforts to protect children from tobacco. $\mathscr{f} A M A$ 1987; $24: 3387-9$.

12 Thomson B, Toffler WL. The illegal sale of cigarettes to minors in Oregon. $\mathcal{Y}$ Fam Med 1990; 31 (2): 206-8.

13 Russ NW, Geller ES. Training bar personnel to prevent drunken driving: a field evaluation. Am $\mathfrak{f}$ Public Health $1987 ; 77: 952-4$ 
$14 \mathrm{McKnight}$ AJ. Development and field test of a responsible alcohol service program. Volume 1: Research Findings. National Highway Traffic Safety Administration, US Department of Transportation, 1987. (Report No DOT HS 807221 .

15 US Bureau of the Census. 1990 Census Report, San Diego County Department of Commerce.

16 Wildey M, Young RL, Elder JP, DeMoor C, Wolf K, Fiske $\mathrm{K}$ et al. Cigarette point-of-sale advertising in ethnic neighborhoods in San Diego, California. Health Val 1992; 16: 23-8.

17 Altman DG, Rasenick-Douss L, Foster V, Tye JB. Sustained effects of an educational program to reduce sales of cigarettes to minors. Am 7 Public Health 1991; $81: 891-3$.

18 DiFranza JR, Carlson RP, Caisse RE. Reducing youth access to tobacco. Tobacco Control 1992; $1(1): 58$

음

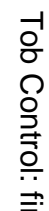

\&.

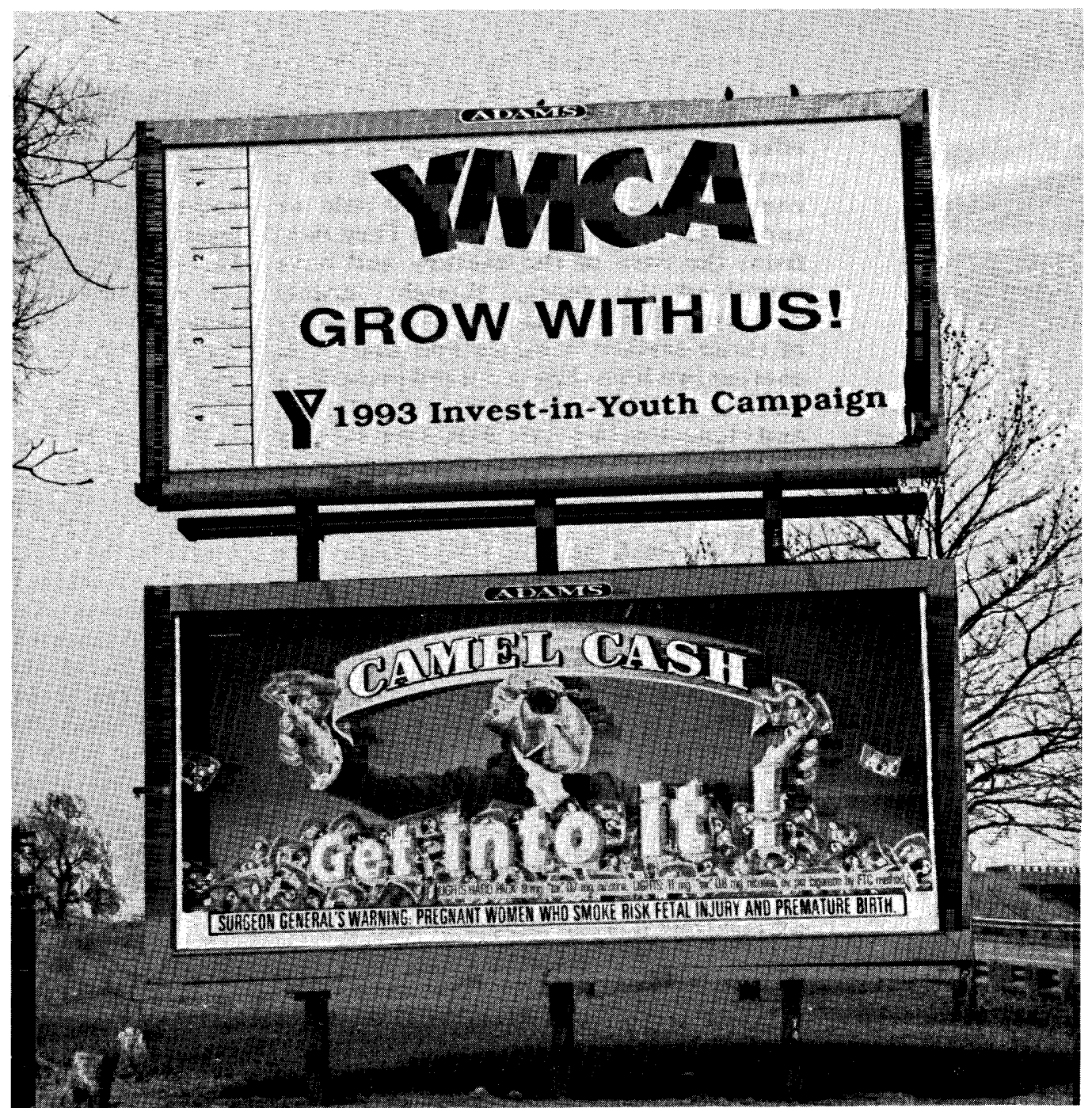

foe Camel investing in youth (Lansing, Michigan, USA, March 1993) 